\title{
Radioisotope Species Name
}

National Cancer Institute

\section{Source}

National Cancer Institute. Radioisotope Species Name. NCI Thesaurus. Code C158322.

The literal identifier of the radioisotope, usually specified as the name of the chemical element followed by the mass number. 